\title{
Precisamos de um Museu do Cinema
}

\author{
Paula Davies Rezende'
}

\section{Resumo}

Neste artigo faço uma análise dos equipamentos de cinema e fotografia por diferentes óticas: como artefato portador de significado e reflexo da dinâmica da sociedade que o criou, como mediador e modificador da relação humana com a imagem técnica e como agente atuante na criação estética. Por fim, trato da necessidade de musealização desses objetos tecnológicos, trazendo como exemplo o acervo de tecnologia cinematográfica da Cinemateca do Museu de Arte Moderna do Rio de Janeiro.

\section{Palavras-chave}

Musealização; Tecnologia; Cinema; Fotografia; Preservação

\section{Abstract}

In this paper I make an analysis of the film and photography equipment by different optics: as artifact bearer of meaning and reflection of the dynamics of the society that created it, as mediator and modifier of the human relation with the technical image and as acting agent in the aesthetic creation. Finally, I address the need to musealize these technical objects and I bring the collection of film technology from the Cinematheque of the Museum of Modern Art of Rio de Janeiro as an example.

\section{Keywords}

Musealization; Technology; Cinema; Photography; Preservation

Foi de uma paixão por câmeras fotográficas antigas que as ideias a seguir começaram a se arranjar. Se quisermos matar a curiosidade de como eram fotografias ou filmes no passado, existem alguns museus ou instituições de guarda onde podemos nos debruçar em imagens de lugares e pessoas que muitas vezes não mais existem. Temos livros, fotolivros, coleções de DVDs, blu-rays, mostras de cinema e canais de televisão dedicados ao assunto. Porém onde vão parar as máquinas que produziram tais imagens?

Apesar de haver uma quantidade considerável de acervos de imagens técnicas $^{2}$, são poucas as instituições que detêm coleções formadas pelos objetos

I Formada em Audiovisual pela Escola de Comunicações e Artes da Universidade de São Paulo, especialista em Preservação de Acervos de Ciência e Tecnologia pelo Museu de Astronomia e Ciências Afins no Rio de Janeiro e mestra em Estética e História da Arte pelo Programa de Pós-Graduação Interunidades em Estética e História da Arte da Universidade de São Paulo.Atualmente trabalha comoTécnica de Preservação de Filmes na Cinemateca Brasileira e pesquisa sobre a agência de elementos não-humanos na produção estética. Contato: paula.rezende@usp.br.

2 O filósofo Vilém Flusser define imagem técnica como "imagem produzida por aparelhos. Aparelhos são produtos da técnica que, por sua vez, é texto científico aplicado. Imagens técnicas são, portanto, produtos indiretos de textos - o que lhes confere posição histórica e ontológica diferente das imagens tradicionais. Historicamente, as imagens tradicionais precedem os textos, por milhares de anos, e as imagens técnicas sucedem aos textos altamente evoluídos. Ontologicamente, a imagem tradicional é abstração de primeiro grau: abstrai duas dimensões do fenômeno concreto; a imagem técnica é abstração de terceiro grau: abstrai uma das dimensões da imagem tradicional para resultar em textos (abstração de segundo grau); depois, reconstituem a dimensão abstraída, a fim de resultar novamente em imagem. Historicamente, as imagens tradicionais são pré-históricas; as imagens técnicas são pós- históricas. Ontologicamente, as imagens tradi- 
tecnológicos envolvidos na sua produção. Por que guardamos, catalogamos, documentamos e preservamos os filmes e fotografias, mas relegamos as câmeras, moviolas, objetivas, projetores e ampliadores à segundo plano? O cinema e a fotografia são frutos de tecnologias que vêm enfrentando uma rápida obsolescência. Seus equipamentos tornam-se ultrapassados e não funcionais em espaços de tempo tão curtos que são insuficientes para despertar interesse histórico. Enquanto as imagens técnicas têm sua necessidade de guarda reconhecida, os objetos tecnológicos que viabilizam sua existência não raro acabam sendo deixados em uma espécie de limbo museológico, armazenados de forma inadequada, esquecidos nas instituições e se deteriorando à olhos vistos, arriscando desaparecem sem terem a chance de contar sua história.

Meu propósito neste artigo é trazer reflexões sobre a urgência da constituição de um museu do cinema que se debruce não apenas sobre o conteúdo das imagens técnicas, mas também - e principalmente - sobre os equipamentos que as viabilizam. É preciso colocar em pauta os acervos tecnológicos de cinema e fotografia. Considero que tal tipologia compreende a gama de objetos que tem como função primária registrar, manipular, editar ou reproduzir imagens técnicas estáticas, em movimento ou som. Neste caso estou propondo examinar o cinema e a fotografia através da mesma perspectiva analítica pois são processos que têm raiz similar, são imagens produzidas e reproduzidas não pelo ser humano sozinho, como o desenho e a pintura, mas sim em uma colaboração humana com a tecnologia ${ }^{3}$.

O reconhecimento das tecnologias cinematográficas e fotográficas como artefatos que podem vir a se despir de seu uso primário e virar portadores de significado, testemunhos retirados de suas realidades originais para poder representá-la, é um passo importante para a musealização e a preservação desses acervos. Portanto, primeiramente trarei uma breve leitura desses objetos tecnológicos no âmbito da Cultura Material. Sob essa perspectiva, um olhar mais detido sobre os artefatos fabricados pelo ser humano contribui para a compreensão da sociedade à qual eles pertenceram, pois são fruto e testemunho dos valores, convicções e especificidades desse contexto $O$ pesquisador de história cultural E. McClung Fleming nos lembra que os registros mais antigos do ser humano incluem objetos. A sobrevivência e auto-realização de uma cultura é absolutamente dependente dos artefatos pertencentes a ela. $\mathrm{O}$ estudo dos artefatos seria então um estudo sobre os seres humanos.

Para conhecer o homem, devemos estudar as coisas que ele fez - 0 Parthenon, o Canal do Panamá, Stonehenge, o computador, o Taj Mahal, a cápsula espacial, a Pietà de Michelangelo, os cruzamentos das autoestradas, a Grande Pirâmide, os autorretratos de Rembrandt. Os artefatos feitos e usados por um povo não são apenas uma expressão básica dessa sociedade; eles são a própria cultura, um meio necessário para a autorrealização do ser humano. (FLEMING, 1999: 153, tradução minha).

cionais imaginam o mundo; as imagens técnicas imaginam textos que concebem imagens que imaginam o mundo. Essa posição as imagens técnicas é decisiva para o seu deciframento” (FLUSSER, 2002: I3).

3 Em seu livro "A Extinção dos Tecnossauros", sobre as tecnologias que fracassaram, o jornalista científico Nicola Nosengo faz diferenciação entre técnica e tecnologia. Técnica seria um termo antigo que diz respeito a um "conjunto de normas sobre o exercício prático de qualquer arte ou atividade". A palavra tecnologia deriva de técnica, foi cunhada na época da Revolução Industrial e trata do "estudo sistemático das técnicas conduzido com métodos científicos". Ou seja, é tecnológico apenas o que foi introduzido durante ou após a Revolução Industrial e são aplicações do saber científico moderno (NOSENGO, 2008: 19-20). Por sua gênese, portanto, o cinema e a fotografia são tecnologias. 
O professor e pesquisador Ulpiano T. Bezerra de Meneses afirma que a cultura material diz respeito ao "segmento do meio físico que é socialmente apropriado pelo homem. Por apropriação social convém pressupor que o homem intervém, modela, dá forma a elementos do meio físico, segundo propósitos e normas culturais". Os artefatos seriam o principal contingente da cultura material, e além de fornecer informações relativas a sua própria constituição física, como matéria prima, morfologia, função, técnica/tecnologia, também reverberam, produzem e reproduzem aspectos da vida social da própria sociedade que os produziu e os consumiu. Para Meneses tais artefatos não devem ser entendidos apenas como produtos, mas também como vetores que canalizam as relações sociais em direções específicas (MENESES, I983: I07-I I3).

Como nesse caso estamos tratando de artefatos ligados à tecnologia, cabe trazer Marcus Granato, pesquisador do Museu de Astronomia e Ciências Afins do Rio de Janeiro. Segundo ele, a cultura material das ciências não está relacionada somente a análise de um objeto por si, mas sim ao levantamento das técnicas e tecnologias que viabilizaram aquele artefato e sua biografia, com qual finalidade foi produzido e qual uso que teve ao longo de sua trajetória. Tais investigações desvendam o vínculo do objeto técnico com o pensamento científico que os originou e com o contexto sócio, econômico, político e cultural no qual foi produzido (GRANATO et al, 2007: p. 2).

Esse olhar para a concepção e trajetória dos artefatos abre significativos caminhos de abordagens da tecnologia cinematográfica e fotográfica no âmbito brasileiro. Devido aos frequentes baixos orçamentos não raro trabalha-se com equipamentos adaptados que tem suas funções primárias desviadas para outras incumbências que se fazem necessárias. $E$ também nos lembra que artefatos tecnológicos não são neutros nem despidos de valores e ideologia, pelo contrário, refletem e canalizam convicções e crenças humanas de seu contexto de produção.

Um exemplo interessante surge quando investigamos a história do desenvolvimento das emulsões fotográficas coloridas. A socióloga Lorna Roth, em artigo para Revista Zum, conta a história dos cartões de calibragem de cor da Kodak. Na década de 1940 a Kodak passou a produzir um cartão com escalas de cinza e de cor, sempre acompanhados da imagem de uma mulher branca, chamada informalmente de Shirley. Os cartões, que serviam para ajudar a definir parâmetros como exposição, densidade e calibragem dos tons de pele que seriam impressos nas imagens, acabaram conhecidos como "cartões Shirley" (Figura I).

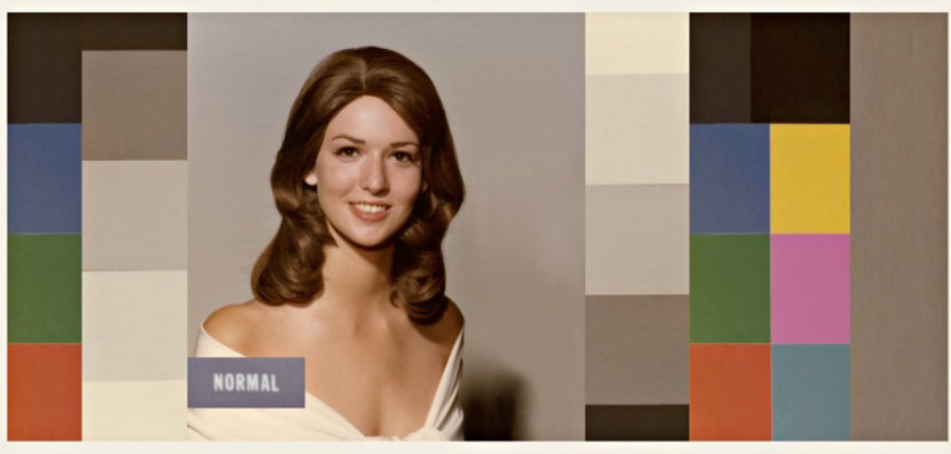

Figura I - Cartão Shirley, usados na definição de parâmetros de densidade, exposição e calibragem dos tons de pele nas ampliações fotográficas. 
Roth observa que, com o passar dos anos, a imagem da mulher variava, mas sempre eram mulheres brancas, jovens e dentro do padrão de beleza ocidental, o que acabava por reforçar um padrão racista e normatizante de tons de pele.Além da ideologia etno-normativa incutida nos cartões Shirley, a química da revelação dos filmes Kodak também favorecia o registro de peles brancas. Independente da calibragem dos aparelhos, a reprodução de tons de peles escuras era insatisfatória, apresentava uma coloração indistinta que dificultava a percepção dos detalhes da face. Só na década de 1960 começou-se a questionar a "química da brancura" da Kodak, percebida pelos fotógrafos das comunidades afro-americanas e consumidores mais críticos (ROTH, 20l6). Em entrevista para a jornalista Suzana Velasco, o fotógrafo brasileiro Eustáquio Neves relata que esse sempre foi um problema na revelação de suas imagens, nas quais prevalecem o registro de pessoas negras. Nas palavras de Neves, "Fotografar uma negra com vestido de casamento branco, por exemplo, era muito difícil. Acabava-se clareando o negro, em vez de retratá-lo. Eu achava que não sabia fotografar, até perceber que o padrão não foi criado para a pele negra" (VELASCO, 20I6). A ideia de que a ciência e a tecnologia são imparciais torna custoso perceber que algo teoricamente neutro, como o desenvolvimento das emulsões fotográfica, havia sido influenciado por crenças subjetivas obtusas que escancaram um profundo racismo institucionalizado. Não só a pesquisa científica e o raciocínio objetivo alicerçam os inventos tecnológicos, negar a existência de um viés ideológico é recusar a ler nas entrelinhas as importantes histórias de luxúrias, medos, ódios e irracionalidades que tais inventos também contam.

Quando falamos do contexto de invenção dos artefatos tecnológicos, é comum atrelar sua descoberta ou desenvolvimento com alguma necessidade do ser humano urgindo para ser sanada. Existe uma frase muito presente no senso comum que diz que "a necessidade é mãe de todos os inventos". Essa crença turva o entendimento das relações sociais entre inventor/produtor, consumidor e objeto, além de limitar a relação de tais artefatos com o imaginário humano. $\bigcirc$ historiador George Basalla analisa a diversidade técnica e tecnológica, e para ele, a ideia de que a produção de novos artefatos se daria apenas como resposta a uma premência de suprir as necessidades básicas do ser humano para garantir a sobrevivência dificulta a compreensão, apreciação e estudo desses objetos como portadores de sentido (BASALLA, 1989:2).

Como exemplo, o autor traz a roda e o carro, invenções emblemáticas na história humana. Com relação à roda, ele conta que os achados arqueológicos mais recentes indicam que ela teria sido inventada na Mesopotâmia há cerca de 5 mil anos atrás, e que os primeiros veículos com rodas eram utilizados em cerimônias e rituais religiosos. Outras pesquisas arqueológicas mostram que veículos com rodas eram também usados nos campos de batalha em guerras. $\bigcirc$ uso de rodas para o transporte de bens e mercadorias não tem evidências arqueológicas tão antigas como os dois descritos anteriormente. Em regiões no sudoeste da Asia, África, Sul do Saara,Australasia, Polinésia, e América do Norte e do Sul a população sobreviveu, e em muitos casos, prosperou, sem a roda, devido a uma geografia desfavorável para a introdução de veículos com rodas. Esse advento teria sido adotado somente nos tempos modernos. Mesmo sem provas concretas, ainda repete-se o argumento que a roda foi inventada por conta da necessidade de se transportar bens agrícolas e que sua função primária era estritamente utilitária (BASALLA, 1989: 7-II).

A invenção do carro tem história similar. Basalla relata que as pessoas viviam normalmente usando transportes baseados em animais de carga até o fim 
do século 19, quando foi inventado o motor de combustão interna. Não havia nenhuma crise de falta de cavalos que ameaçasse a oferta de carroças, e nem havia uma demanda específica por parte da população por transportes motorizados. Pelo contrário, quando surgiu, o carro era um luxo, um brinquedo para quem tinha muito dinheiro e que pudesse comprar um (BASALLA, 1989:6-7).

Ambos os casos relatados acima demonstram que, para além de suprir à necessidades elementares e fundamentais para sobrevivência humana, tais artefatos - assim como a emulsão fotográfica colorida da Kodak - derivam sua invenção de um contexto sócio-cultural, de ideologias e valores específicos. Basalla traz para a discussão o filósofo Gaston Bachelard, que nos alenta: "a conquista do supérfluo nos dá um estímulo espiritual maior do que a conquista do necessário, porque os seres humanos são criações de desejo, não da necessidade" (BACHELARD apud BASALLA, 1989:4). Estudar os artefatos é também buscar saber sobre os sonhos, medos, luxúrias e fantasias do ser humano. Em um workshop ocorrido na Mostra de Cinema de Ouro Preto (CINEOP) em 2018, o filósofo espanhol Jorge Larossa Bondía menciona que, ensinar cinema na escola é apresentar para os alunos a máquina que faz maravilhas. Investigar essas máquinas que fazem maravilhas é também tomar nota das nossas tão importantes desnecessidades.

Convém lembrar que o cinema e a fotografia estão estreitamente ligados à atividade simbólica do ser humano e à elaboração de representações. $O$ professor e pesquisador Arlindo Machado afirma que a história da arte não diz respeito apenas à história das ideias e invenções estéticas, mas é principalmente a história dos recursos e expedientes que permitem aos seres humanos expressar tais ideias e invenções. Ele relaciona, também, a produção cultural e artística com as técnicas e tecnologias que viabilizam sua expressão: seria impensável haver transformações tecnológicas sem o consequente desenvolvimento da arte e da cultura, e vice-versa. Pensar a produção artística como fruto apenas da genialidade de um indivíduo e negar a atuação de outros elementos neste processo, inclusive os não-humanos, seria portanto uma distorção (MACHADO, 1993: II-12).

Apesar de serem imprescindíveis para diversas variantes da produção simbólica humana, a posição que as máquinas e outros objetos tecnológicos ocupam na arte e na cultura ainda é dúbia. O filósofo e tecnólogo Gilbert Simondon, que se debruça sobre a gênese e o papel do que ele chama de objetos técnicos, afirma que a cultura se colocaria como um obstáculo que separa e "defende" o ser humano das técnicas, como se as máquinas e ferramentas não fossem, na realidade, fruto da intenção e do esforço humano. Segundo o autor, a separação entre as técnicas e outros tipos de produção humana configura-se como uma forma de alienação, uma falha na compreensão da natureza e essência da máquina, o que faz com que seja mantida fora do domínio dos significados. Seguindo esse raciocínio, a cultura seria uma faca de dois gumes: por um lado reconhece certos objetos, tais como os objetos de cunho estético, garantindo a eles um lugar cativo no mundo dos significados; por outro, bane diversos objetos, especificamente os de cunho técnico, apesar de sua capacidade de materializar informações de forma única, e os relega ao mundo prosaico das coisas que não tem significado, mas tem utilidade. A cultura, conclui o autor, falha em reconhecer a humanidade que se encontra na realidade técnica, mas para cumprir sua missão de forma plena, deveria reconhecer o papel desta como mediadora entre a dimensão humana e a natureza, além de aceitar que ela também faz parte de seu domínio (SIMONDON, 1980: I-2). 
A noção da máquina como mediadora entre ser humano e mundo físico tem desdobramentos em outros teóricos. $O$ antropólogo Bruno Latour junto com os sociólogos Michel Callon e John Law introduzem, na década de 1980, a Teoria Ator-Rede (ANT), que diz respeito à atuação de elementos não-humanos na atividade social. Latour afirma que a tendência da sociologia tradicional é restringir o social aos seres humanos, ignorando que sua esfera é mais ampla e não necessariamente centrada no indivíduo. A ANT então coloca os artefatos técnicos e tecnológicos conectados em uma rede, junto com outros elementos humanos e não-humanos. A ANT propõe uma revisão do papel atribuído aos elementos não-humanos, reconhecendo-os como atores e não apenas projeções simbólicas, capazes de "[...] um tipo de ação mais aberto que a tradicional causalidade natural - e mais eficiente que a simbólica [...]" (LATOUR, 2012: 24-30).

De acordo com Latour, no domínio da sociologia tradicional os objetos não eram considerados como atores, ou seja, capazes de ação, pois entendia-se a ação como necessariamente intencional ou significativa, características inexistentes em elementos não-humanos. Para a ANT, qualquer elemento que possa fazer diferença e modificar uma situação é um ator. Isso não quer dizer que os objetos desempenhem funções atribuídas apenas aos seres humanos, mas sim que nenhuma ciência do social pode existir, de forma plena, sem que todos os elementos que participam da ação sejam completamente explorados. Até porque, raramente o curso de uma ação baseia-se apenas em conexões humanas ou apenas em conexões entre objetos, mas muito frequentemente ziguezagueia entre ambas (LATOUR, 2012: 108-I I3).

Ainda no âmbito da ANT, Latour traz dois conceitos imperativos para o estudo de objetos tecnológicos, que são as definições de agentes intermediários e os mediadores. Para o autor, um intermediário exerce uma ação ou transporta uma informação sem transformá-la, o que entra é o mesmo que sai. Os mediadores, por sua vez, alteram, distorcem e transfiguram os elementos e significados que veiculam, o que entra nunca define o que sai e sua especificidade deve ser sempre levada em conta. Segundo o autor, "Um mediador, apesar de sua aparência simples, pode se revelar complexo e arrastar-nos em muitas direções que modificarão os relatos contraditórios atribuídos a seu papel" (LATOUR, 20I 2: 65). A partir dessa definição, é possível pensar os objetos tecnológicos de cinema e fotografia como mediadores. Por exemplo, a câmera. A luz que entra através da objetiva de uma câmera é transformada e desviada por um jogo de lentes e espelhos até chegar em uma superfície sensível, onde será registrada. A forma como a cena tridimensional existente no mundo visível será traduzida em imagem bidimensional, na superfície sensível, depende da especificidade dos diversos mediadores, como o tipo de objetiva, tamanho da superfície sensível, tipo de emulsão (no caso da imagem analógica) ou o tipo do algorítmo (no caso da imagem digital). Nesse ponto cabe trazer o filósofo Vilém Flusser. Para ele, os fótons e elétrons que emanam do mundo físico junto com a luz, originalmente não significam nada. $\bigcirc$ aparelho, que recebe esses fótons e eletróns e os transforma em imagem, é que produz vetores de significados ${ }^{4}$. Mais do que simples refletores, tais aparelhos seriam projetores, capazes de traduzir informações codificadas do mundo físico em forma de imagem (FLUSSER, 2009: 52-53).

4 Aparelho produtor de imagens técnicas é um termo utilizado por Vilém Flusser que engloba câmeras fotográficas, cinematográficas, câmeras digitais e computadores, capazes de criar imagens virtuais. São dispositivos técnicos que transformam fótons, elétrons e bits de informação em imagem, capacidade essa que as mãos e os olhos não têm, já que tais elementos não são palpáveis. Cf. FLUSSER, 2009, p. 24. 
Flusser afirma que transformação do mundo físico em imagens técnicas não se dá apenas a partir da subjetividade do ser humano, como ocorre com o desenho e a pintura, mas é também determinada pela câmera. $O$ agente produtor da fotografia, por exemplo, seria o complexo "aparelho-operador", responsável por conectar imagem e significado.

No caso das imagens tradicionais, é fácil verificar que se trata de símbolos: há um agente humano (pintor, desenhista) que se coloca entre elas e seu significado. Este agente humano elabora símbolos "em sua cabeça", transfere-os para a mão munida de pincel, e de lá, para a superfície da imagem. A codificação se processa "na cabeça" do agente humano, e quem se propõe a decifrar a imagem deve saber o que se passou em tal "cabeça”. No caso das imagens técnicas, a situação é menos evidente. Por certo, há também um fator que se interpõe (entre elas e seu significado): um aparelho e um agente humano que o manipula (fotógrafo, cinegrafista). Mas tal complexo "aparelho-operador" parece não interromper o elo entre a imagem e seu significado. Pelo contrário, parece ser canal que liga imagem e significado. (FLUSSER, 2002: I5).

Arlindo Machado partilha da mesma perspectiva de Flusser, enfatizando especificamente o papel do que ele denomina de máquinas semióticas - relacionadas à criação de representações. Essas máquinas desempenhariam funções ligadas à representação na atividade simbólica do ser humano, pois teriam expressividade própria e capacidade de criar significados.

Elas [as máquinas semióticas] "falam", elas determinam modos de percepção, elas incutem ideologias pelo que têm de "saber" materializado em suas peças e circuitos, pela sua maneira particular de tornar sensível o mundo de que elas são a mediação e pela sua específica resolução do problema da codificação desse mesmo mundo. (MACHADO, 1993: 34-35).

Ao se referir especificamente à câmera fotográfica, Machado observa que elas estabelecem uma espécie de diálogo com as informações luminosas que emanam do mundo visível, e que teriam uma "[...] força formadora mais que reprodutora", sendo elas responsáveis por suas próprias estruturas simbólicas: mais do que reproduzir passivamente, elas dão significado às informações luminosas provenientes do mundo físico, construindo representações (MACHADO, 2015: 14).

Autores como Latour, Flusser e Machado nos instigam a encarar não só a câmera, mas os objetos tecnológicos de cinema e fotografia sob outra luz. Longe de serem meros acessórios sem significância, são mediadores indispensáveis para que um filme ou uma foto - os produtos finais de um processo complexo - possam existir. Atrelar as análises formais de estética e conteúdo puramente à intencionalidade humana, sem investigar as tecnologias e demais elementos não-humanos que cooperaram em sua produção, incorre em deixar de fora um encadeamento significativo de informações, prejudicando a percepção e entendimento que temos do próprio processo de produção simbólica. Tanto que a ideia de autoria ainda é comumente conferida exclusivamente ao ser humano que pensa, planeja e projeta. Porém as máquinas também intervêm na concepção das imagens no íntimo de seu mecanismo, podendo determinar traços estéticos ou atributos formais, que, não raro, fogem da vontade ou intencionalidade 
de quem apertou o botão.

Um bom exemplo pode ser observado nos filmes $8 \mathrm{~mm}$ e Super 8 , bitolas comuns em filmes domésticos e experimentais desde meados do século 20 até a década de 1990, quando seu uso declinou devido ao aumento da popularidade do vídeo. É comum encontrar filmes de família nessa bitola guardados em caixas de sapatos junto com fotos antigas. Devido ao fato de serem armazenados em locais que não são ideais para sua preservação, possivelmente esses filmes apresentam marcas da ação do tempo e da deterioração: a imagem predominantemente magenta, marcada por fungos, sujidades e intempéries diversas. Essa imagem $8 \mathrm{~mm}$ ou Super 8 , tão marcada em nossa memória quando pensamos em filmes domésticos, é fruto da especificidade de um tipo de câmera, de película, de revelação e de envelhecimento que acumulam vestígios estéticos no filme que chega até nossos olhos. Uma câmera portátil como as usadas nessas bitolas podia ser usada sem tripé, contando com a estabilidade que os braços humanos poderiam dar, usualmente resultando em registros instáveis e com foco suave. A película reversível - vendida em cartuchos para facilitar o manuseio - já era revelada em material colorido e positivo, o que favorecia sua produção e consumo por entusiastas e amadores, mas dificultava à confecção de novas cópias. A película colorida, armazenada em ambiente inadequado, favorecia a proliferação de fungos, o aparecimento de riscos e sujeiras, o esmaecimento dos pigmentos coloridos. Essas características estéticas, que se manifestam à revelia da vontade humana, compõem um imaginário coletivo e remetem à memórias afetivas de um tempo e espaço que já passaram, muitas vezes relacionadas ao ambiente doméstico familiar. Um exemplo dessa associação é a vinheta de abertura do seriado estadunidense Anos Incríveis, exibido na televisão brasileira em meados da década de 1990. Apesar de ser produzido no fim dos anos 1990, a narrativa do seriado se passa nos anos de 1960 e 1970, então a vinheta de abertura explora o imaginário doméstico dessa época, materializado nas roupas das personagens, na trilha sonora e na estética da imagem, uma emulação do filme Super 8mm já deteriorado, com riscos e imagem tremida (Figura 2).

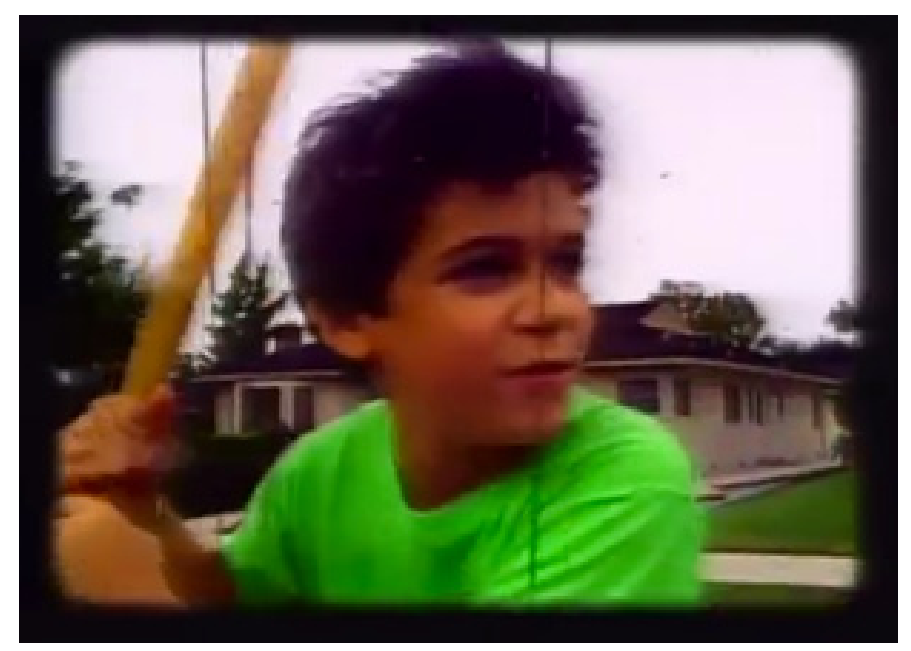

Figura 2 - Imagem da vinheta de abertura do seriado "Anos Incríveis".

Outro exemplo da determinação estética por atores não-humanos é a glitch art, um tipo de apropriação estética de falhas tecnológicas. A artista e pesquisadora holandesa Rosa Menkman define o glitch como "quebra (real e/ou simulada) de um fluxo de informação ou significado esperado ou convencional, 
no âmbito do sistema de comunicação (digital), que resulta em um acidente ou erro percebido" (MENKMAN, 20l I: 9). Apesar de inicialmente o glitch dizer respeito a um erro ocorrido acidentalmente no processamento eletrônico e reverberado na imagem, diversos artistas passaram a buscá-lo intencionalmente, forçando falhas através da manipulação de algoritmos ou mesmo o sobrecarregamento das funções da máquina. No fim dos anos 2000, o glitch popularizou-se e trespassou a bolha dos artistas experimentais. Uma breve busca nas lojas de aplicativos de celular Android ou Apple retorna com diversos apps que emulam falhas de processamento nas imagens que o usuário selecionar. $O$ cantor estadunidense Kanye West usou a estética no clipe da sua música "Welcome to Heartbreak", de 2008, explorando imagens que parecem ter sido corrompidas por problemas de processamento da máquina (Figura 3).

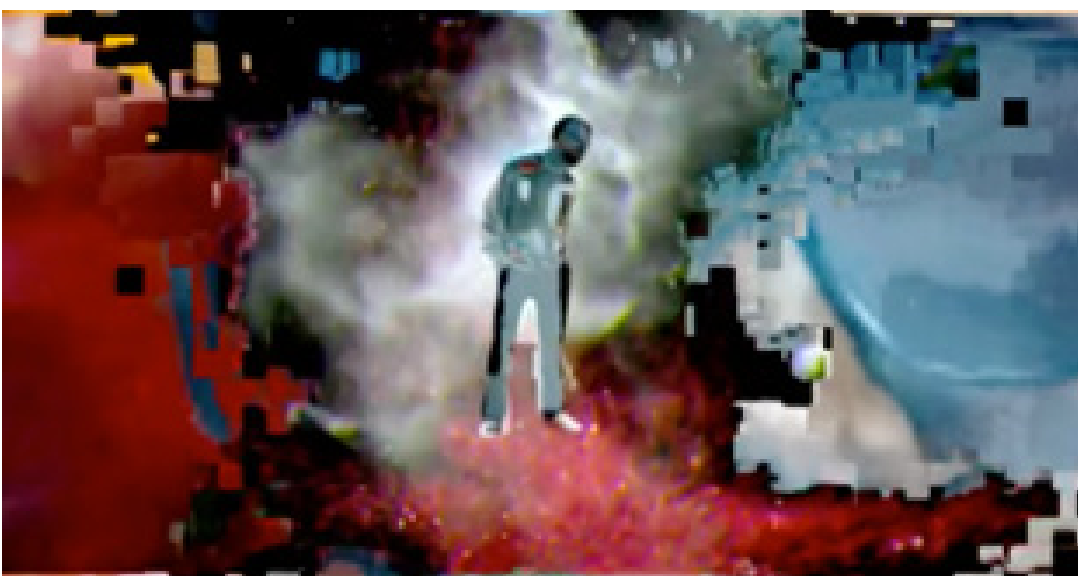

Figura 3 - Imagem do videoclipe "Welcome to Heartbreak" (2008), de Kanye West.

Além de investigar a atuação dos objetos tecnológicos na produção de imagens técnicas, é fundamental constatar como eles também alteram a experiência de recebimento e percepção dessas mesmas imagens. Um bom exemplo é a história do som no cinema. Nas primeiras décadas de cinema - entre o fim do século 19 e início do século 20 -, o cinema ainda era mudo, ou seja, não tinha uma trilha sonora sincronizada diretamente com às imagens. Os filmes eram então acompanhados por músicos ao vivo, que executavam a trilha sonora. Mais tarde, os músicos foram substituído por discos, que eram colocados para tocar ao mesmo tempo que o filme. Como os músicos ou os discos reproduziam apenas músicas, e não diálogos, o sincronismo - ou a falta dele - não era muito crítico. Por volta de 1928, com os títulos "Cantor de Jazz" e "Don Juan", o sistema óptico de som registrado na própria película se torna viável comercialmente. O "Cantor de Jazz" até apresenta sincronismo labial dos atores com suas falas (KLACHQUIN, 20I0).A relação do espectador com o cinema então muda radicalmente. As imagens, anteriormente acompanhadas apenas por músicas, agora tem também diálogos sonoros. A trilha sonora acaba por ser suplantada pela voz dos atores, que passa a ter lugar substancial na narrativa sonora. Com a possibilidade de haver diálogos em tempo real, articulados com o movimento dos lábios dos atores, a forma como se pensa a narrativa é alterada. Junto com o som, a sala de cinema sofre diversas alterações e uma delas é o tamanho e a capacidade de espectadores. Em 1944, o Cine Marabá, no centro de São Paulo, era uma sala com capacidade para 1.655 pessoas, equipado com uma grande tela. Na reforma de 2009 o espaço foi transformado em cinco salas, uma com capacidade para aproximadamente 450 pessoas, as outras com capacidade pra 
aproximadamente 150 pessoas, com telas significativamente menores. Ver o filme numa sala com I 50 pessoas ou com I.500 são experiências diferentes. Muito diferente ainda de assistir o mesmo filme na televisão de casa, na tela do computador ou mesmo no celular. $O$ aparato técnico que reproduz o filme modifica sua fruição e a própria forma como os produtos audiovisuais são produzidos. É diferente pensar em um enquadramento para ser projetado na tela grande do cinema ou para ser reproduzido em dispositivos móveis.

Nesse sentido, é fundamental pensar também na preservação do contexto de fruição de um filme na época de seu lançamento. Quando preservamos a película cinematográfica, o suporte analógico ou digital que armazena o filme ou o som, estamos guardando o conteúdo, a informação. Mas para preservar a experiência de percepção dessa informação é necessário levar em conta toda uma estrutura que engloba telas de projeção, caixas de som, poltronas, salas, projetores, enfim, elementos que complementam a experiência cinematográfica para além do suporte informacional.

É preciso e urgente, então, guardar essa miríade de objetos, que juntos documentam o cinema e sua história não apenas como conteúdo informacional, mas como experiência simbólica, tátil e sensorial. É necessário uma instituição de guarda cuja missão seja acolher, documentar e preservar esses artefatos. Precisamos de um museu do cinema.

O museu, segundo a museóloga Waldisa Rússio é justamente o lugar que trabalha a relação entre ser humano e objeto, entre o ser humano e a sua realidade (RÚSSIO, 1984: 60-62). Segundo Ulpiano Meneses, esta é a instituição cuja incumbência é coletar, classificar e preservar objetos, com a intenção de colocá-los à disposição para pesquisa, exposição, de forma a promover o acesso público àquela fonte de informações. $O$ museu é responsável pela transformação institucional de um objeto em documento, pois, ao ser incorporado ele é destituído da função primária para a qual foi concebido, ou para qual foi utilizado no decorrer de sua trajetória, e vira um artefato simbólico, portador de informação. O museu induz o olhar para aquilo que passa despercebido no cotidiano, chama atenção para aquilo que é diferente e contextualiza em termos sociais, econômicos e políticos. Este seria o lugar para nos defrontarmos com os objetos e seus diversos usos e significados (MENESES, 1995: 3-4).

É por isso que um relógio, numa coleção, deixa de ser um artefato que marca a hora: ninguém coleciona relógios para cronometrar o tempo com maior precisão. Numa coleção (e na coleção institucionalizada do museu), o relógio, ainda que funcione, passa a ser um artefato que fornece informação sobre os artefatos que marcam a hora. (MENESES, 1995: 4).

A constituição de um acervo museológico contribui para o estreitamento das nossas relações com o mundo material que nos circunda e é um importante passo para a democratização da percepção sensorial, da experiência, do conhecimento e da fruição do que nos é simbólico e significativo. Inevitavelmente, no museu se somam as dimensões cognitivas e racionais com as afetivas (MENESES, 1994: 12-14).

Ao me referir a um museu do cinema, cabe aqui discorrer sobre o que seria o escopo de tal instituição e qual sua especificidade com relação às outras instituições relacionadas à memória da imagem e do som, com por exemplo a Cinemateca Brasileira em São Paulo, e a Cinemateca do Museu de Arte Mo- 
derna, no Rio de Janeiro. Segundo Laura Bezerra, professora da Universidade Federal do Recôncavo da Bahia (UFRB), tais cinematecas, criadas em meados do século 20, foram as duas primeiras do Brasil, e surgiram em um contexto de valorização do cinema nacional, até então desqualificado por não conseguir se constituir como indústria nem se firmar como arte ${ }^{5}$.Ambas tiveram como base inicial um acervo fílmico, visando estimular a difusão e reflexão sobre a cultura cinematográfica (BEZERRA, 2015: 196-197). Para além de salvaguardar filmes, precisamos de um lugar que se debruce sobre os equipamentos e tecnologias que os trouxeram à vida. Diversas instituições relacionadas fotografia e cinematografia, assim como a Cinemateca Brasileira e a Cinemateca do MAM-RJ, detém equipamentos em seu acervo, mas esses não são alvos prioritários de documentação, pesquisas, políticas de preservação, que, por diversos motivos - incluindo escassez de recursos - acabam por mirar o acervo fílmico. Para o estabelecimento de um museu do cinema da forma como é sugerido neste artigo, não é necessária a criação de uma nova instituição, mas sim uma reorientação da missão e diretrizes institucionais já existentes, de forma a abranger as coleções de tecnologia nos planos e ações de preservação e difusão.

A proposta não é criar um museu-catálogo, que faça uma taxonomia de equipamentos fotográficos e cinematográficos e os exiba enfileirados e ordenados por data ou tipologia. Tal configuração não raro busca estabelecer uma ilusão teleológica de unidade, linearidade e progresso, estéril se comparada à perspectiva crítica que pode assumir um espaço expositivo. Um museu do cinema seria um lugar para reconhecer fragmentos, rupturas, contradições e conflitos. Problematizar a tecnologia sem a parcialidade do discurso da indústria e da publicidade que parecem infalivelmente exaltar os últimos lançamentos, as novas funcionalidades, os muitos mega pixels.

Também não é a intenção que um museu do cinema seja o lugar que proveja aura benjaminiana para artefatos que por sua gênese industrial não a teriam, através, por exemplo, do procedimento de destacar equipamentos utilizados por celebridades cinematográficas para registrar obras proeminentes, como se fossem o santo sudário do cinema. Não seria o lugar para tratar objetos tecnológicos tal qual relíquias, como se houvesse um significado imanente. Meneses nos lembra que as únicas propriedades inatas de um objeto são de natureza físico-química: forma, matéria-prima, cor, peso, densidade. Os demais atributos, de cunho afetivo, sensorial, estético e político, não são características dos artefatos - ilusão que incorre na fetichização e reificação dos objetos -, mas sim da sociedade que os produziu, os colocou em circulação, os consumiu e posteriormente os descartou (MENESES, 1994: 26-27). Um museu do cinema deve então costurar as relações dos artefatos com o contexto no qual estiveram inseridos. Por exemplo, tratar a relação da diminuição do tamanho e peso das câmeras com o estabelecimento de novas linguagens imagéticas, ou o desenvolvimento das emulsões fotográficas coloridas e o racismo institucionalizado, ou as relações entre as mudanças nas tecnologias de registro imagético e a constante busca por uma suposta fidelidade de representação do mundo visível.

No caso da musealização de objetos técnicos e tecnológicos, de cunho não apenas simbólico mas também utilitário, como seria o caso dos equipamentos de cinema e da fotografia, existe uma discussão no campo da museologia sobre a necessidade de serem esvaziados de suas funções quando incorporados

5 A Filmoteca do Museu de Arte Moderna de São Paulo, que viria a se tornar a Cinemateca Brasileira, foi criada em 1949. O Departamento de Cinema do Museu de Arte Moderna do Rio de Janeiro, que depois viria a ser chamado de Cinemateca, surgiu em 1955. 
à uma instituição de guarda. Será que um objeto produzido com um objetivo utilitário cumpre plenamente sua missão de documentar a realidade da qual foi retirado se estiver impossibilitado de exercer suas funções dentro de um museu? Um museu do cinema possivelmente passaria por esse questionamento, já que não seria descabido haver demanda de pesquisadores e usuários para manusear alguns objetos, para fruí-los da forma que foram programados em seu contexto originário, de onde foram retirados. Essa procura costuma ser comum em museus de ciência, técnica e tecnologia, que lidam com objetos de cunho utilitário. O Science Museum de Londres, na Inglaterra, que detém importantes coleções de ciência, tecnologia, indústria e transportes, por exemplo, tem documentado uma política específica de operação de objetos. O museu acredita que os "altos níveis de interesse e valor educacional em 'objetos funcionais' proporcionam conexões significativas entre os visitantes do museu e as coleções", portanto eles informam que selecionam objetos para serem usados de forma segura e sustentável (POLICY, 20I4: 3).

De fato, o uso e manuseio de objetos provenientes da técnica e tecnologia parecem propiciar uma experiência ampla e positiva, porém existem problemas nessa prática. Ao permitir que um artefato museológico seja colocado em uso, não estaríamos também contribuindo para seu desgaste, danificação e deterioração? Por outro lado, é difícil separar de forma pragmática o que pode virar acervo museológico e o que ainda será necessário no uso corrente no laboratório de uma cinemateca ou arquivo de filmes. As tecnologias já obsoletas que teriam espaço garantido em um espaço expositivo não raro são necessárias para processar películas e outros suportes informacionais, muitas vezes também já obsoletos. Então mesmo que alguns equipamentos nem estejam mais no uso corrente, é possível que ainda possam servir como repositório de peças para outros que ainda funcionam nos laboratórios. Por serem obsoletos, peças de reposição não são mais fabricadas, então por vezes a única possibilidade de conserto jaz na canibalização de outros exemplares. Essa sem dúvida é uma importante discussão e que deverá ser levada a cabo em espaço mais amplo e oportuno que este artigo.

De qualquer forma, a musealização é uma importante forma de preservação, não só do conteúdo informacional, mas também de toda uma gama de artefatos que permite que esse conteúdo seja acessado, reproduzido, projetado, duplicado e fruído.

Nesse contexto, proponho-me a falar da Cinemateca do MAM-RJ. Além do acervo de filmes, a instituição guarda uma coleção significativa de tecnologia cinematográfica. O pesquisador José Luiz de Araújo Quental conta a história da instituição. O Museu de Arte Moderna do Rio de Janeiro (MAM-RJ) foi criado em 1948, como uma instituição privada, sem fins lucrativos. Entre seus fundadores estavam banqueiros, empresários e funcionários de alto escalão do Estado. Em 1955 surge o Departamento de Cinema, que depois viria a ser chamado de Cinemateca, fruto dos esforços de Ruy Pereira da Silva, um jornalista e produtor cultural muito atuante na promoção do cinema brasileiro dentro e fora do país. $O$ intuito era colocar o cinema entre as principais atividades do museu, como acontecia em outras instituições ligadas à arte moderna fora do Brasil. Apesar de estar ligada ao MAM-RJ, a Cinemateca tem uma identidade própria, e "ao longo de toda sua trajetória foi enxergada como entidade autônoma ao restante da instituição, com uma história que pode ser refletida e escrita à parte" (QUENTAL, 20I0, p. 75-78).

A atividade principal da Cinemateca é a guarda e conservação de filmes 
e documentação relacionada à produção audiovisual brasileira. $\mathrm{O}$ acervo filmográfico contém diferentes suportes, como películas $35 \mathrm{~mm}, 16 \mathrm{~mm}, 8 \mathrm{~mm}$, Super 8 e fitas magnéticas. $O$ acervo documental conta com cartazes de filmes, reportagens, fotografias e toda sorte de documentos relativos à produção audiovisual nacional, reunidos ao longo da trajetória da instituição. A coleta, guarda e preservação de objetos tecnológicos não era missão principal da instituição, e se deu de forma fragmentada e não documentada.

O estado de conservação do acervo no geral é ruim, mas existem variações.Algumas peças encontram-se em melhor estado, muitas vezes por estarem protegidas por estojos ou invólucros eficientes. Outras peças são mais sensíveis às intempéries específicas do local. A Cinemateca está localizada no Aterro do Flamengo, há apenas alguns metros da Baia de Guanabara, então a maresia é presença constante e afeta principalmente os metais, matéria-prima de diversos objetos do acervo.

Diante de um acervo sem documentação, a história acumulada e transmitida de forma oral no dia-a-dia dos funcionários, no fazer das rotinas de trabalho, se torna fonte valiosa e peça-chave na coleta e compreensão de informações sobre esse acervo.Visando ter acesso a tais informações, realizei em outubro de 2012 uma entrevista aberta com Hernani Heffner, conservador-chefe do arquivo de filmes da Cinemateca do MAM-RJ ${ }^{6}$, responsável pelos acervos audiovisuais e de equipamentos. Trechos da entrevista, que foi gravada em áudio, foram transcritos a seguir.

Os aproximadamente oitocentos objetos pertencentes a esse acervo são de diferentes proveniências. Infelizmente, em nenhuma dessas diferentes incorporações, os objetos foram documentados, resultando em um acervo sem registro, ficha catalográfica, termo de aquisição, termo de doação ou qualquer documento que forneça informações sobre a identidade ou histórico do artefato. Segundo Heffner, parte dos objetos chegou através de comodato, feito por particulares que depositaram na instituição equipamentos que eram de seu próprio uso profissional mas já estavam obsoletos ou não eram mais utilizados. Outra parte são incorporações, feitas pelos próprios funcionários da instituição. Mas na origem da coleção de objetos tecnológicos da Cinemateca do MAM-RJ está o acervo do Museu de Cinema, idealizado pelo cineasta, historiador e pesquisador Jurandyr Passos Noronha (1916-2015). Segundo Laura Bezerra, ele foi fundamental na história do cinema brasileiro e na construção de uma cultura de preservação audiovisual no Brasil. Noronha foi crítico e cronista, tendo escrito para jornais e publicações ligadas ao cinema. Também atuou como diretor, cinegrafista, historiador, colecionador e preservacionista audiovisual. Trabalhou em empresas produtoras e no Departamento de Imprensa e Propaganda (DIP) do governo Getúlio Vargas, antes de iniciar sua carreia no Instituto Nacional de Cinema Educativo (INCE)7 ${ }^{7}$, em 1948. Com o fim do INCE, em 1966, Noronha passa a trabalhar no seu órgão sucessor, o Instituto Nacional de Cinema (INC) ${ }^{8}$,

6 Hernani Heffner é formado em Comunicação Social - Cinema pela UFF. Entrou para a Cinédia em 1986, como pesquisador, permanecendo na companhia até 1999, onde coordenou a restauração ou duplicação da maioria dos títulos sobreviventes da empresa. Em 1996 entrou para Cinemateca do MAM, onde exerceu o cargo de Curador de Documentação e passou em 1999 a Conservador-Chefe do Arquivo de Filmes. Foi professor da UFF, Estácio, Candido Mendes, FGV, CINETV-FAP e desde 2005 leciona na PUC-Rio. Foi Curador do Festival Cine Música de 2007 a 2014, e da temática preservação da Mostra de Cinema Ouro Preto - CineOP, de 2012 a 2016.

7 O Instituto Nacional de Cinema Educativo (INCE) foi criado em 1936 criado pelo governo de Getúlio Vargas, com o intuito de implementar e difundir o cinema como ferramenta educativa e ideológica. Foi o primeiro órgão estatal brasileiro voltado para o cinema (GALVÃO, 2004: 17).

8 O Instituto Nacional de Cinema (INC) foi instituído durante o Regime Militar, em 1966, para promover 
atuando na direção da Filmoteca e do Museu de Cinema. Com a extinção do INC, Noronha assume na Embrafilme ${ }^{9}$ a responsabilidade pela Divisão de Pesquisa e História do Cinema (BEZERRA, 2015: 205). O cineasta também teve importante atuação como colecionador, e constituiu ao longo dos anos uma coleção formada por fotografias, periódicos, recortes, cartas, filmes e equipamentos relacionados à produção cinematográfica brasileira. Com excessão dos filmes e equipamentos cinematográficos, que estão depositados na Cinemateca do MAM-RJ, o restante da coleção encontra-se o Museu de Imagem e Som do Rio de Janeiro (MORAES, 2006: 57).

\begin{abstract}
Na origem, quem construiu o Museu de Cinema foi o cineasta, pesquisador, historiador, e funcionário público chamado Jurandyr Passos Noronha. O Jurandyr, ali nos anos 60 , se dedicou ao passado da cinematografia Brasileira de duas formas. De um lado, ele acabou desenvolvendo uma série de filmes sobre figuras do passado, dos quais o mais conhecido é o Panorama do Cinema Brasileiro, que é antologia, uma compilação de trechos de filmes antigos brasileiros, ele meio que elabora uma história. De outro lado ele acabou constituindo a ideia de um Museu de Cinema, que ele organizou timidamente pela primeira vez em 1970 no então já INC. (HEFFNER, 20I2).
\end{abstract}

Não há clareza sobre os laços institucionais do Museu de Cinema e a quem juridicamente fato pertenciam as peças dessa coleção. Segundo Heffner, foi Noronha que reuniu o acervo ao longo de sua vida, como funcionário do Estado brasileiro e como pesquisador autônomo. Por exemplo, na época em que realizou entrevistas com personalidades pioneiras do cinema brasileiro para seu documentário "Panorama do Cinema Brasileiro" (1968), Noronha recebeu doação de diversos equipamentos cinematográficos em desuso, que passaram a constituir parte do Museu de Cinema. Essa relação não foi documentada, não há Termo de Doação ou outro documento que ateste a transferência de propriedade.

A quem pertencia o Museu de Cinema? Ao Estado Brasileiro? Nunca houve uma definição nesse sentido. [...] E de fato, do pouco que me lembro de documentação lá pra trás, por exemplo, é dessa exposição em 1970. Não é uma exposição do INC, é uma exposição no INC, com as peças reunidas pelo Jurandyr. [...] E todo mundo patrimoniou naquela de "tá aqui, vou patrimoniar", mas cadê o documento que diz que era do INCE, do INC, da Embrafilme ou que era do MAM? Na verdade nunca houve um documento que dissesse formalmente que aqui está um certo conjunto de peças, que eu estou em colocando em comodato, pelo menos eu nunca tive acesso, e desconfio que nunca existiu de fato. $O$ que na prática existia era isso, uma entidade chamada Museu de Cinema do Jurandyr, que

e estimular o desenvolvimento das atividades cinematográficas no país, tendo o objetivo de formular e executar a política governamental relativa a produção, importação, distribuição e exibição de filmes, desenvolvimento da indústria cinematográfica brasileira, seu fomento cultural e sua promoção no exterior. Em 1975 foi extinto, e suas atribuições transferidas para a Embrafilme (INSTITUTO, 20I6).

9 A Empresa Brasileira de Filmes (Embrafilme) foi uma empresa estatal brasileira produtora e distribuidora de filmes. Tinha a função de fomentar a produção e distribuição de obras cinematográficas nacionais, além da regulação e fiscalização.A Embrafilme foi criada em 1969 e extinta em 1990, por conta do Programa Nacional de Desestatização, promovido pelo governo Collor (EMBRAFILME, 2018). 
- Jurandyr a títulos vários foi reunindo... E ele no fim das contas constituiu essa entidade, e essa entidade não tinha de fato, digamos assim, um registro oficial. (HEFFNER, 20I2).

Houve, em 1978, nova exposição do Museu de Cinema, dessa vez na Funarte $^{10}$, que dividia o espaço com o Museu Nacional de Belas Artes, na Avenida Rio Branco, no Rio de Janeiro. Noronha era a pessoa responsável pela organização, e estava sempre presente no local, guiando os visitantes e falando sobre as peças.

Há nas fontes da época uma dubiedade, as vezes era o Museu de Cinema montado pelo Jurandyr, as vezes era o Museu de Cinema encampado pela Funarte... Enfim. Não há uma clareza sobre quem é de fato o dono daquelas peças. $E$ até onde eu possa perceber, e eu lembro, o Museu ficou pouco tempo aberto, eu lembro de ir visitar e lembro de ver o Jurandyr lá. E o Jurandyr era a pessoa que guiava, organizava, falava sobre as peças. Tudo dava acesso a ele. Eu não sei se houve um acordo para que a Funarte abrigasse, e em abrigando pediu para eventualmente se associar. Esse tipo de documento, se existiu, eu nunca vi e nem nunca chegou nada aqui no MAM. (HEFFNER, 20I2).

Após o fim da exposição de 1978, a Funarte recusou-se a continuar abrigando o acervo, que seguiu para a Embrafilme.A Embrafilme alegou dificuldade no armazenamento das peças, que eram grandes e tomavam bastante espaço. Enfim o acervo foi enviado para a Cinemateca do MAM-RJ, onde passou boa parte de sua história sem uma documentação que atestasse posse, depósito ou procedência.

A solução encontrada na época foi encaixotar tudo, e esses caixotes acabaram sendo colocados na Embrafilme. A Embrafilme, por sua vez, disse: "não tenho o que fazer com esses caixotes, não é meu, não quero isso aqui". A Embrafilme acabou fazendo uma consulta à Cinemateca, na verdade ao Cosme [Alves Neto' '] , e o Cosme falou: "ah manda pra cá, a gente fica com isso". E aí os caixotes vieram pra cá, em 1980. E ficaram encaixotados também, que a Cinemateca disse que recebia, mas não fez nada com isso, de imediato. Um dos funcionário, o Zé Roberto Moraes, trabalhava na parte de filme, mas em certa altura cansou daquele universo e resolveu trabalhar com outra coisa. Aí ele resolveu mexer com isso e simplesmente abrir essas caixas. Que que tem dentro dessas caixas? É o Museu de Cinema.Tudo bem, mas o que que tem dentro, o que de fato é esse Museu de Cinema? Nesse momento que o Zé Roberto começou a abrir as caixas, eu já fazia um estágio informal aqui na Cinemateca, perambulava pra lá e pra cá, e quando vi as caixas me interessei. O Zé Roberto então disse; "ah, então vamos tirar tudo de dentro das caixas, vamos limpar, vamos ver o que que é e vamos fazer uma listagem", aí a gente começou a compilar. (HEFFNER, 20I2).

10 A Fundação Nacional de Artes (Funarte) foi criada em 1975 com a finalidade de promover, estimular, desenvolver atividades culturais em todo o Brasil. Atualmente é o órgão responsável, no âmbito do Governo Federal, pelo desenvolvimento de políticas públicas de fomento às artes visuais, à música, ao circo, à dança e ao teatro (FUNARTE, 20I0).

II Cosme Alves Neto assumiu a direção da Cinemateca do MAM-RJ em 1964, cargo que ocupou por cerca de 30 anos. 
Em 1993 a Cinemateca sofreu um grande furto, e perdeu importante parte do acervo oriundo do Museu de Cinema. Em 1994 mais um furto, em que foi perdida outra parte de grande valor histórico do mesmo acervo. Segundo Heffner, mesmo após tais incidentes o Estado brasileiro não se pronunciou nem reclamou posse das peças, quem se pronunciou foi Noronha, afirmando que as peças do Museu de Cinema eram suas. Das cerca de trezentos e cinquenta peças que eram originalmente do Museu de Cinema, sobraram menos de cem. Esses dois acontecimentos tão marcantes na história do acervo refletem a importância de se pensar na segurança física da instituição, seja a contratação de equipe especializada, uso de equipamentos de vigilância ou a organização e controle de pessoas autorizadas a ter acesso a chaves e dispositivos de abertura e trancamento de salas e prédios.

Entre 1994 e 2002 foram incorporadas ao acervo mais peças, provenientes de doações que aconteciam de forma assistemática e também não foram documentados. Eram, porém, artefatos sem tanta expressão quanto o que haviam sido roubados anteriormente.

Em 2002 a direção do MAM concluiu que a Cinemateca não tinha condições de abrigar o acervo de objetos tecnológicos, que foi oficialmente doada para o Instituto para Preservação da Memória do Cinema Brasileiro, organização não governamental dirigida por Alice Gonzaga, filha de Adhemar Gonzaga, falecido jornalista e cineasta dono da Cinédia ${ }^{12}$. A coleção ficou armazenada no próprio estúdio da empresa, em Jacarepaguá, Rio de Janeiro. Quando a Cinédia encerrou suas atividades, em 2007, a coleção voltou para a Cinemateca do MAM-RJ, em forma de comodato. A ela haviam sido incorporados muitos objetos e equipamentos de uso da própria produtora, já que essa havia fechado suas portas de vez.

Atualmente Hernani Heffner e uma reduzida equipe da Cinemateca estão trabalhando na recuperação dos artefatos da coleção de objetos tecnológicos, higienizando e realizando pequenas intervenções. Também foi iniciado o processo de catalogação, porém como não há financiamento específico para o projeto, o processo é mais lento. Agora, no final de 2018, está em cartaz no MAM-RJ a exposição "Galáxia(s) do Cinema: máquinas, engrenagens, movimentos ou this strange little thing called love" sobre tecnologia cinematográfica, que tem curadoria de Heffner e apresenta algumas das peças do acervo do Museu de Cinema. Segundo informações da própria instituição, a exposição apresenta

[...] uma visão evolutiva da cinematografia brasileira, destacando seus instrumentos de criação mais decisivos, singulares ou persistentes. Sem encobrir a relação umbilical entre a obra fílmica e os equipamentos, insumos e materiais que a compuseram, além dos artistas que as utilizaram, modificaram ou reinventaram, a exposição procura lançar um amplo olhar sobre as peças e documentos que compõem não só a criação como a vivência do cinema. (MAM. $\mathrm{RIO}, 2018)$.

O caso da Cinemateca do MAM-RJ nos revela a trajetória instável de uma importante coleção de objetos tecnológicos em uma das principais instituições

12 A Cinédia foi um estúdio cinematográfico criado em 1930, no Rio de Janeiro. Dedicou-se à produção de dramas populares e comédias musicais, conhecidas como "chanchadas". Alguns filmes produzidos pela Cinédia foram: "Limite" (193I), dirigido por Mário Peixoto, "Ganga Bruta” (1933), dirigido por Humberto Mauro e "O Ébrio" (1946), dirigido por Gilda de Abreu (CINÉDIA, 20I8). 
de memória cinematográfica do país.Apesar das adversidades e perdas ao longo do caminho, boa parte dos artefatos deu conta de sobreviver até os dias de hoje. É exercício penoso, porém indispensável, reconhecer que muitos testemunhos e documentos da história da tecnologia cinematográfica se foram, com a perda de parte inestimável do acervo, nos furtos de 1993 e 1994. Porém, no atual cenário de subvalorização das instituições de guarda - visto incêndio ocorrido no Museu Nacional, no Rio de Janeiro, em setembro desse ano -, conceber uma exposição de tecnologia cinematográfica como a que está em cartaz no MAM-RJ é ato de resistência e deve ser reconhecido como tal.

Pensar o cinema e a fotografia de forma crítica, além da habitual análise dos produtos finais, demanda um espaço de confronto e reflexão sobre os demais agentes que fazem tais imagens, estáticas e em movimento, acontecerem. É urgente que criemos um espaço onde os objetos tecnológicos sejam armazenados, documentados e estudados com o devido cuidado e segurança. Um lugar onde eles não estejam apenas esperando para serem descartados ou desmontados para virar peça para outros equipamentos. Precisamos de um museu do cinema.

Referências

BASALLA, George. The Evolution of Technology. Cambridge, UK: Cambridge University Press, 1989.

BEZERRA, Laura. Construindo um espaço para a preservação audiovisual no Brasil. Revista Alceu, PUC-Rio, v. I5, n. 30, p. I95-2I 0, jan./jun, 20I5.Acesso em I4 de jan 2019. Disponível em <http://revistaalceu.com.puc-rio.br/media/Alceu\%20 30\%20pp\%20195\%20a\%20210.pdf>

CINÉDIA. In:WIKIPEDIA, 2018. Disponível em: <https://pt.wikipedia.org/wiki/ Cinédia $>$.Acesso em 02 nov 2018.

EMBRAFILME. In: WIKIPEDIA, 2018. Disponível em: <https://pt.wikipedia.org/ wiki/Embrafilme>, Acesso em: 02 nov 2018.

FLEMING, E. McClung. Artifact Study: a proposed model. In: SCHLERETH, Thomas J. (org). Material Culture Studies in America. Walnut Creek, California:Altamira Press, 1999.

FLUSSER,Vilém. Filosofia da caixa preta: ensaios para uma futura filosofia da fotografia. Rio de Janeiro: Relume Dumará, 2002.

FLUSSER, Vilém. $O$ universo das imagens técnicas elogio da superficialidade. São Paulo:Annablume, 2009.

FUNARTE. In: FUNDAÇÃO Nacional de Artes, 2010. Disponível em: <http:// www.funarte.gov.br/a-funarte/>.Acesso em: 02 nov 2018.

GALVÃO, Elisandra. A ciência vai ao cinema: uma análise de filmes educativos e de divulgação científica do Instituto Nacional do Cinema Educativo (INCE). Dissertação (Mestrado - Pós-Graduação em Educação, Gestão e Difusão em Biociências do Departamento de Bioquímica Médica) - Universidade Federal do Rio de Janeiro, Rio de Janeiro, 2004. Acesso em I4 jan 2019. Disponível em $<$ http://www.casadaciencia.ufrj.br/Publicacoes/Dissertacoes/acienciavaiaocinema.pdf>.

GRANATO, Marcus et al. Objetos de Ciência e Tecnologia como Fontes Documentais para a História das Ciências: Resultados parciais. In: Encontro Nacional da Associação Nacional de Ciência da Informação e Biblioteconomia, 8, 2007, Salvador. 
Anais... Salvador: Associação Nacional de Ciência da Informação e Biblioteconomia, 2007.

HEFFNER, Hernani. Depoimento [out. 2012]. Entrevistadora: Paula Davies Rezende. Rio de Janeiro, 20I2. 3 arquivos digitais.

INSTITUTO Nacional de Cinema. In: GUIA do Instituto de Estudos Brasileiros (IEB), 20I6. Disponível em: <http://www.ieb.usp.br/instituto-nacional-de-cine$\mathrm{ma} />$.Acesso em: 02 nov 2018.

KLACHQUIN, Carlos. O Som no Cinema. Associação Brasileira de Cinematografia, jun. 20 I0. Disponível em <http://www.abcine.org.br/artigos/?id=I 2 | \&/o-som-no-cinema>. Acesso em: II out 2018.

LATOUR, Bruno. Reagregando o social: uma introdução à teoria do ator-rede. Salvador: Edufba, 2012.

MACHADO, Arlindo. Máquina e imaginário: o desafio das poéticas tecnológicas. São Paulo: Edusp, 1993.

MACHADO,Arlindo. A ilusão especular: uma teoria da fotografia. Barcelona: Gustavo Gili, 2015.

MAM.RIO. In: INSTAGRAM, 8 set 20I8. Disponível em: <https://www.instagram. com/p/BneZqdnhOpf/>. Acesso em: 02 nov 2018.

MENESES, Ulpiano Toledo Bezerra.A cultura material no estudo das sociedades antigas. Revista de História, n. I 15, p. 103-I I7, 1983.

MENESES, Ulpiano T. Bezerra de. Do Teatro da Memória ao Laboratório da História: exposição museológica e conhecimento histórico. Anais do Museu Paulista, São Paulo: USP, v.2, 1994.

. Para que serve um museu histórico? In: Como explorar um museu histórico. São Paulo: Museu Paulista, 1995.

MENKMAN, Rosa. The glitch moment(um). Amsterdam: Institute of Network Cultures, 20II. Disponível em: <http://www.networkcultures.org/_uploads/ NN\#4_RosaMenkman.pdf>.Acesso em: 02 nov 2018.

MORAES, Kely Cristina Silva de. A Memória do Cinema Mudo Brasileiro na coleção Jurandyr Noronha. 2006. 99p. Dissertação (Mestrado - Programa de Pósgraduação em Memória Social). -Universidade Federal do Estado do Rio de Janeiro, Rio de Janeiro, 2006. Acesso em: 14 jan 2019. Disponível em <http:// www.memoriasocial.pro.br/documentos/Dissertações/Diss 199.pdf>.

NOSENGO, Nicola. A extinção dos tecnossauros. Tradução: Regina Silva. Campinas: Editora Unicamp, 2008.

POLICY and procedures for selecting and operating historic objects from the collections of the Science Museum Group. 2014. Disponível em: <https://group. sciencemuseum.org.uk/wp-content/uploads/2018/06/SMG-Policy-Selecting-Operating-Objects-Approved-20 |4-newbrand.pdf>. Acesso em: 12 out 2018. QUENTAL, J. L. A. A preservação cinematográfica no Brasil e a construção de uma cinemateca na Belacap: a Cinemateca do Museu de Arte Moderna do Rio de Janeiro. 2010. Dissertação (Mestrado em Comunicação) - Universidade Federal Fluminense, Niterói, 2010.

ROTH, Lorna. Questão de pele. Revista Zum, n. 10, 23 jun. 2016. Disponível em: $<$ https://revistazum.com.br/revista-zum-I0/questao-de-pele/>. Acesso em: 24 out 2018.

RÚSSIO, Waldisa. Cultura, Patrimônio e preservação, texto III. In:ARANTES, Antônio Augusto (org.). Produzindo o passado. São Paulo: Brasiliense/CONDEPHAAT, 1984.

SIMONDON, Gilbert. On the Mode of Existence of Technical Objects. Tradução: Ninian Mellamphy. Ontario: University of Western Ontario, 1980. 
VELASCO, Suzana. Sob a luz tropical: racismo e padrões de cor da indústria fotográfica no Brasil. Revista Zum, n. 10, I3 jul. 2016. Disponível em: <https://revistazum.com.br/revista-zum-10/racismo-padroes-industria-brasil/>. Acesso em: $24 / 10 / 2018$ 